\title{
Short term histological liver changes in extrahepatic biliary atresia with good postoperative bile drainage
}

\author{
A DESSANTI, R OHI, M HANAMATSU, I MOCHIZUCHI, T CHIBA, AND M KASAI
}

Department of Paediatric Surgery, Ospedale dei Bambini Umberto I, Brescia, Italy and IInd Department of Surgery and Division of Paediatric Surgery, Tohoku University School of Medicine, Sendai, Japan

SUMMARY Short term histological liver changes were studied in 13 patients with congenital biliary atresia, who showed good bile drainage after radical operation. Biopsies obtained at the time of the corrective surgery and at the second operation to convert from external total to partial bile drainage (undertaken once the bilirubin concentration was less than $30 \cdot 8 \mu \mathrm{mol} / \mathrm{l}$ ) were compared.

A significant correlation was found between histological findings and the clinical course. In particular, at the second biopsy an increase in hepatic fibrosis and cell infiltration was observed mainly in patients whose bilirubin concentration decreased slowly or who had cholangitis, or both. Hepatic fibrosis and cell infiltration had decreased, however, in an appreciable number of patients whose postoperative course had been characterised by a rapid reduction in the bilirubin concentration and no cholangitis.

Congenital biliary atresia was always a fatal disease until Kasai first described the original surgical technique of 'hepatic portoenterostomy' in 1959.' If the radical operation is performed in younger babies, restoration of bile flow after operation and resolution of jaundice is obtained in about $63 \% .^{2}$

Many long term histological studies of patients with congenital biliary atresia who have undergone operation resulting in good bile drainage and no evidence of jaundice, have reported progressive hepatic fibrosis and cirrhosis. ${ }^{34}$ Progressive hepatic fibrosis has not always been observed, however, and indeed in some patients this has actually decreased. ${ }^{56}$

We report the short term, histological changes in the liver after radical operation for congenital biliary atresia and their relation to the clinical course of the disease.

\section{Materials and methods}

Thirteen patients (five boys and eight girls) with congenital biliary atresia (10 with type III, three with type I disease according to the Japanese Society of Paediatric Surgeons classification $)^{7}$ who underwent operation at Tohoku University Hospital between January 1982 and June 1984 (Fig. 1), were selected for this study according to the following criteria: (1) they were operated on at an early age ranging between 47 and 77 days (12 patients underwent a hepatic portoenterostomy, and one (case no 2, Fig. 1) a hepatic jejunostomy, in all cases with external biliary drainage according to Suruga II technique); (2) they all achieved good postoperative bile drainage; (3) they underwent a second operation aged between 148 to 330 days to convert the Suruga II to Kasai II drainage when the total serum bilirubin concentration was less than $30 \cdot 8 \mu \mathrm{mol} / \mathrm{l}$.

Liver biopsies were obtained at the time of the two operations. Specimens sectioned $6 \mu$ in thickness were fixed in $10 \%$ formalin, embedded in paraffin, and finally stained with hematoxylin-eosin and Azan-Mallory staining. Histological evaluation was carried out without previous knowledge of the patient's clinical state. Twelve histological parameters outlined in the results section were evaluated.

The degree of histological changes between the first and second biopsies were compared with clinical data, as shown in Fig. 1, and with the following clinical parameters: (1) degree of resolution of jaundice-deemed rapid or slow if the bilirubin concentration two months after operation was less or more than $25.6 \mu \mathrm{mol} / \mathrm{l}$; (2) cholangitis before the second operation; (3) jaundice at follow up (bilirubin more than $18.8 \mu \mathrm{mol} / \mathrm{l}$ ). 


\begin{tabular}{|c|c|}
\hline $\begin{array}{l}\text { Case } \\
\text { No }\end{array}$ & $\begin{array}{l}\text { Type } \\
\text { CBA }\end{array}$ \\
\hline 1 & $a_{1}-\frac{\text { II }}{-2}$ \\
\hline 2 & $\begin{array}{l}I \text { cos } \\
c_{1}-\alpha\end{array}$ \\
\hline 3 & \\
\hline 4 & \\
\hline 5 & \\
\hline 6 & \\
\hline 7 & \\
\hline 8 & 0, III \\
\hline 9 & \\
\hline 10 & $b_{1}-\frac{\text { II }}{2}$ \\
\hline 11 & $\underset{a_{2}-\nu}{\text { III }}$ \\
\hline 12 & $a_{2=-v}^{\text {II }}$ \\
\hline 13 & $\begin{array}{r}\text { III } \\
a_{2}-0\end{array}$ \\
\hline
\end{tabular}

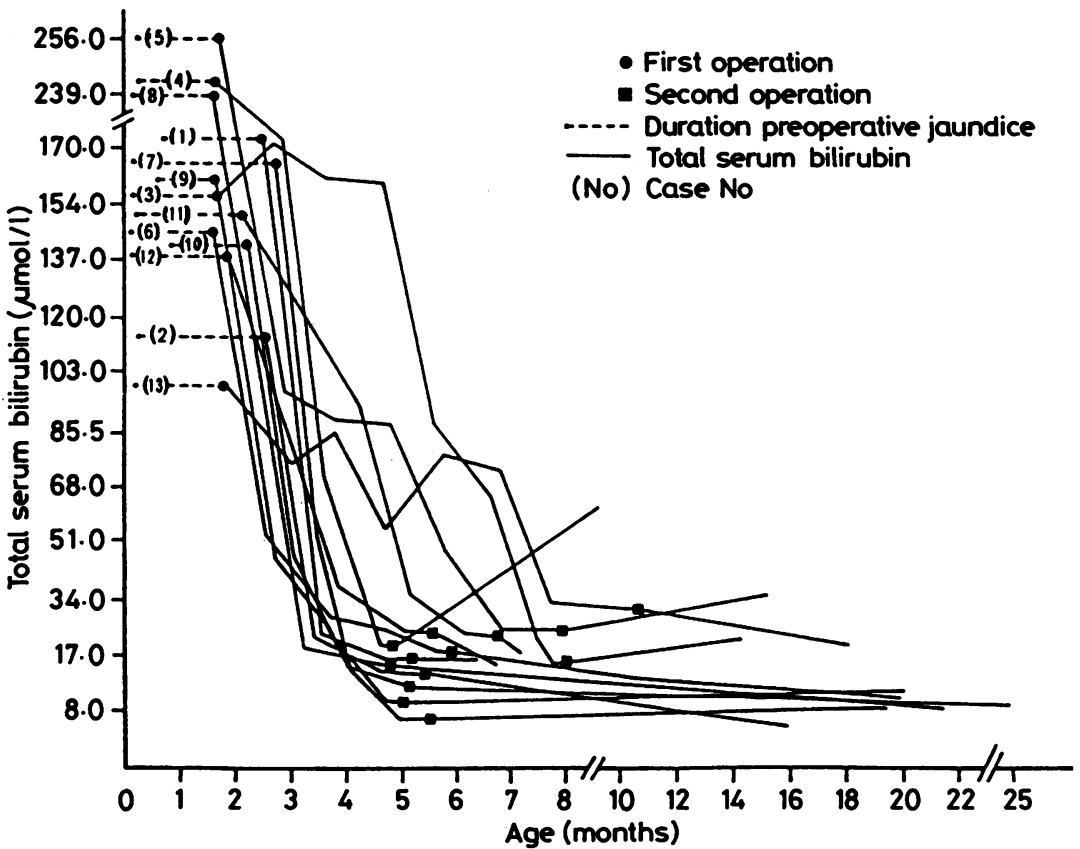

Fig. 1 Clinical data on 13 patients with congenital biliary atresia (CBA). CBA is graded according to Japanese Society of Pediatric Surgery classification. ${ }^{7}$

Conversion-SI to traditional units: total bilirubin $1 \mu \mathrm{mol} / \mathrm{I} \approx 0.05 \mu \mathrm{g} / \mathrm{dl}$.

\section{Results}

\section{Histopathological findings.}

Interlobular area

Portal fibrosis. (Figure 2). The degree of portal fibrosis was classified into four groups: $(-)$ not evident; $(+)$ minimal fibrosis in the vicinity of portal area; $(++)$ moderate fibrosis with narrow interlobular linking; $(+++)$ severe fibrosis with wide interlobular linking or cirrhosis.

The degree of portal fibrosis at the time of the first biopsy could not be correlated with surgical results, but the second biopsy was less in four patients, the same in two, and worse in seven. Four of these seven patients had suffered one or more episodes of cholangitis in the postoperative period and six had shown a slow decrease in the bilirubin value; at present four of the six are jaundiced.

Portal ductal proliferation and periportal ductular proliferation. (Figure 2 , graded - to ++ ) The variation in portal ductular proliferation and periportal ductal proliferation at the first biopsy was not statistically significant. At the second biopsy the former was reduced in one patient and the latter in two patients respectively. In these patients the bilirubin concentration decreased rapidly, cholangitis did not occur, and no jaundice was observed at follow up. Two patients in whom both portal ductal and periportal ductular proliferation increased showed a slow reduction in bilirubin values: one of these has had cholangitis and is jaundiced at present.

Cell infiltration. (Figure 2, graded - to +++ ) Cell infiltration at the first biopsy was variable and could not be correlated statistically. At the second biopsy, six patients showed a reduction in cell infiltrationfour of these patients have had a rapid reduction in jaundice, no cholangitis, and no jaundice at follow up. Four of the remaining seven patients with constant or increased cell infiltration suffered cholangitis, however, and four were jaundiced at follow up.

Portal cholestasis and periportal cholestasis. (Figure 2 graded - to +++ ). Portal cholestasis was observed in five patients at the first biopsy, four of whom showed a slow decrease in bilirubin and cholangitis postoperatively. At the second biopsy 


\begin{tabular}{|c|c|c|c|c|c|c|c|c|c|c|}
\hline \multirow[b]{2}{*}{$\begin{array}{l}\text { Case } \\
\text { No }\end{array}$} & \multicolumn{6}{|c|}{$\begin{array}{l}\text { Interlobular } \\
\text { area }\end{array}$} & \multicolumn{3}{|c|}{$\begin{array}{c}\text { Intralobular } \\
\text { area }\end{array}$} & \multirow[b]{2}{*}{ 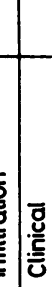 } \\
\hline & 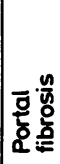 & 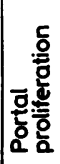 & 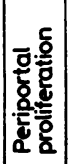 & & 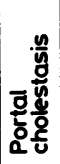 & 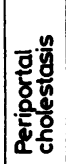 & 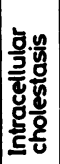 & 대융 & 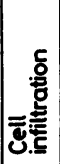 & \\
\hline 1 & $\begin{array}{l}H \\
H\end{array}$ & $\begin{array}{l}H \\
H\end{array}$ & $\begin{array}{l}H \\
H\end{array}$ & + & - & - & $\begin{array}{l}+ \\
+\end{array}$ & + & + & $\stackrel{0}{\rightarrow}$ \\
\hline 2 & $\begin{array}{l}H \\
H\end{array}$ & $\begin{array}{l}+ \\
+ \\
\end{array}$ & $\begin{array}{l}+ \\
+\end{array}$ & $\begin{array}{l}+ \\
+ \\
\end{array}$ & $\overline{-}$ & $\overline{-}$ & + & \pm & \pm & $\underset{\rightarrow}{0}$ \\
\hline 3 & H & $\begin{array}{l}H \\
H\end{array}$ & $\begin{array}{l}H \\
H\end{array}$ & $\begin{array}{l}+ \\
+\end{array}$ & $\begin{array}{l}+ \\
+\end{array}$ & 世 & $\begin{array}{l}+ \\
+\end{array}$ & + & + & 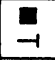 \\
\hline 4 & + & $\begin{array}{l}H \\
H\end{array}$ & H & $\begin{array}{l}H \\
H\end{array}$ & $\overline{-}$ & \pm & + & $\begin{array}{l}+ \\
+\end{array}$ & + & $\stackrel{\square}{-1}$ \\
\hline 5 & H & H & $\begin{array}{l}H \\
H\end{array}$ & + & + & + & + & $\begin{array}{l}+ \\
+\end{array}$ & $\begin{array}{l}+ \\
+\end{array}$ & 픔 \\
\hline 6 & $\begin{array}{l}+4 \\
+ \\
\end{array}$ & $\begin{array}{l}H \\
+\end{array}$ & $\begin{array}{l}H \\
H\end{array}$ & $\begin{array}{l}+ \\
+ \\
\end{array}$ & $\overline{-}$ & $\overline{-}$ & \pm & $\begin{array}{l}+ \\
+ \\
\end{array}$ & $\begin{array}{l}+ \\
+ \\
\end{array}$ & 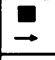 \\
\hline 7 & Ht & $\begin{array}{l}H \\
H\end{array}$ & $\begin{array}{l}H \\
+\end{array}$ & + & \pm & $\begin{array}{l}+ \\
+\end{array}$ & $\begin{array}{l}+ \\
+\end{array}$ & \pm & \pm & $\stackrel{0}{\rightarrow}$ \\
\hline 8 & $\begin{array}{l}+ \\
+ \\
\end{array}$ & $\begin{array}{l}H \\
H\end{array}$ & $\begin{array}{l}H \\
H\end{array}$ & \pm & $\overline{-}$ & \pm & $\begin{array}{l}+ \\
+ \\
\end{array}$ & \pm & \pm & $\stackrel{0}{\rightarrow}$ \\
\hline 9 & $\begin{array}{l}+4 \\
+ \\
\end{array}$ & $\begin{array}{l}H \\
H\end{array}$ & $\begin{array}{l}+ \\
+ \\
\end{array}$ & $\begin{array}{l}+ \\
+\end{array}$ & $\overline{-}$ & $\overline{-}$ & $\begin{array}{l}+ \\
+ \\
\end{array}$ & $\overline{-}$ & \pm & $\stackrel{0}{\rightarrow}$ \\
\hline 10 & $\begin{array}{l}\# \\
\mathrm{H}\end{array}$ & $\begin{array}{l}H \\
H\end{array}$ & $\begin{array}{l}H \\
H\end{array}$ & $\begin{array}{l}\text { W } \\
+\end{array}$ & $\overline{-}$ & \pm & \pm & $\begin{array}{l}+ \\
+ \\
\end{array}$ & $\begin{array}{l}+ \\
+ \\
\end{array}$ & $\stackrel{0}{\rightarrow}$ \\
\hline 11 & $\begin{array}{l}H \\
H\end{array}$ & H & H & + & + & + & $\stackrel{+}{+}$ & $\stackrel{+}{+}$ & + & $\rightarrow$ \\
\hline 12 & $\begin{array}{l}+ \\
+\end{array}$ & + & $\bar{H}$ & $\begin{array}{l}\text { m } \\
H\end{array}$ & $\overline{-}$ & $\overline{-}$ & $\begin{array}{l}+ \\
+ \\
\end{array}$ & $\begin{array}{l}+ \\
+\end{array}$ & $\begin{array}{l}+ \\
+\end{array}$ & $\stackrel{\square}{\rightarrow}$ \\
\hline 13 & + & $\begin{array}{l}+ \\
+\end{array}$ & + & + & \pm & \# & + & H & + & 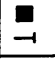 \\
\hline • & 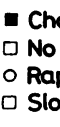 & & . & & tice & & & & & \\
\hline
\end{tabular}

Fig. 2 Histological data and clinical course in 13 patients with congenital atresia.

The top line refers to the first biopsy findings and the lower line to the second biopsy findings.

portal cholestasis was seen in three patients, two of whom were jaundiced at follow up. Periportal cholestasis was seen almost universally at the first biopsy and was still present at the time of the second biopsy in three patients, two of whom had cholangitis, and one of whom was still jaundiced at follow up.

\section{Intralobular area}

Ballooning degeneration. (Figure 2, graded - to $++)$ This was present in all patients at the first biopsy, but was much more severe in six. In four of the six the postoperative course was characterised by a slow decrease in the bilirubin concentration and at follow up three patients were still jaundiced. At the time of the second biopsy ballooning degeneration was seen in some patients in whom it had been severe at the first biopsy.

Intracellular cholestasis. (Figure 2, graded - to ++ ) Intracellular cholestasis was minimal in six patients at the first biopsy. In five of these the clinical course was characterised by a slow reduction in the bilirubin value and three were jaundiced at follow up. Moderate cholestasis was also observed at the time of the second biopsy but there was no correlation with the clinical course of disease.

Intracanalicular cholestasis. This was observed in all patients at first biopsy and was absent in all at the second.

Focal necrosis. (Figure 2, graded - to ++ ) Focal necrosis was severe at first biopsy in five patients, all of whom showed a slow reduction in the bilirubin concentration. It was still present at the second biopsy in four patients who had suffered cholangitis in the postoperative period and three of these were jaundiced at follow up.

Intralobular fibrosis. (Graded - to ++ ) This was observed in all the patients at the first biopsy. At the second it was the same or increased in seven patients, four of whom had suffered one or more episodes of cholangitis.

Cell infiltration. (Figure 2, graded - to +++ ) $\mathrm{A}$ severe degree of cell infiltration at first biopsy correlated with a slow reduction in the bilirubin concentration. Cell infiltration was still present in eight patients at the second biopsy. Six of these showed a slow reduction in the bilirubin concentration and four suffered one or more episodes of cholangitis. Only one of six patients showing a rapid decrease in bilirubin and no cholangitis had an increase in cell infiltration.

\section{Discussion}

If at the time of an early hepatic portoenterostomy there is satisfactory functional connection between the residual fibrous biliary ducts at the porta hepatis and the intrahepatic biliary tree, bile flow may be re-established progressively and jaundice may resolve in a few weeks. The long term prognosis, however, of patients operated on successfully for congenital biliary atresia is still controversial.

In 13 patients who had good bile drainage with regression of bilirubin to normal or almost normal 
values after operation, we studied histological changes in the liver three to nine months after the curative operation. A significant number of patients showed a reduction in fibrosis and cell infiltration on the second liver biopsy. Clinically these patients had a rapid decrease in the bilirubin concentration and no cholangitis. Most patients with increased fibrosis and cell infiltration, however, showed a slow reduction in bilirubin and cholangitis in the postoperative period.

Among the histological parameters considered at the time of the first biopsy the following seemed to indicate a favourable prognosis: (1) absence of cholestasis in portal area; (2) low degree of focal necrosis; (3) moderate hepatocytic ballooning; (4) moderate lobular infiltration; (5) severe intracellular cholestasis.

The absence of portal cholestasis would mean a satisfactory functional connection between proliferated biliary ducts and ductules and interlobular bile ducts (and their minor branches).

The severity of intracellular cholestasis reflects the capacity of liver cells to pick up biliary pigment thereby showing minor liver cell dysfunction.

Some authors have reported the persistence of cell infiltration for a period of many years after operation in patients without jaundice, independent of the type of curative intervention and of cholangitis in the postoperative period. ${ }^{4}$ In our series some patients showed a reduction in cell infiltration: their postoperative course was characterised by a rapid reduction in the bilirubin concentration and no cholangitis. Increased cell infiltration was observed, however, in patients with cholangitis in the postoperative period, suggesting that cell infiltration per se, not specific for congenital biliary atresia, may decrease rapidly if the clinical course is not complicated by other factors such as cholangitis or persistent cholestasis.

Untreated portal fibrosis progresses rapidly with age in congenital biliary atresia. At the age of 4 to 6 months clear histological evidence of hepatic cirrhosis is usually observed. Severe hepatic fibrosis at the time of operation implies less possibility of satisfactory biliary drainage.

The degree of hepatic fibrosis at the first biopsy could not be correlated with clinical results because our patients were young and fibrosis was, in general, moderate. Many follow up studies report an increase in fibrosis even when the corrective operation has resulted in a good bile drainage and resolution of jaundice. ${ }^{34}$ These results have been explained by classifying congenital biliary atresia as a progressive, antenatal liver disease although the biliary obstruction has been cured surgically. ${ }^{48}$

In contrast with these reports the results from the present short term, follow up study seem to indicate that the increase in hepatic fibrosis after corrective operation need not necessarily occur-indeed in about $30 \%$ of patients a decrease was observed together with an improvement in other histological parameters.

As the clinical course of patients with improved liver histology was characterised by a rapid decrease in the bilirubin concentration and absence of cholangitis, we believe that future strategies in the treatment of this disease should aim to secure as satisfactory a bile flow as possible in order to reduce the risk of cholangitis, which remains the most dangerous complication in the postoperative period and may compromise irreparably the success of the operation.

Supported by research funds of IInd Department of Surgery Tohoku University School of Medicine and Ospedale dei Bambini Umberto I.

\section{References}

' Kasai M, Suzuki S. A new operation for 'non-correctable' biliary atresia; hepatic porto-enterostomy. Shujutsu 1959;13: 733-9. (in Japanese).

2 Kasai M. Advance in treatment of biliary atresia. Jpn J Surg 1983;4:265-76.

3 Altman RP, Chandra R, Lilly JR. Ongoing cirrhosis after successful porticoenterostomy in infants with biliary atresia. J Pediatr Surg 1975;10:685-91.

${ }^{4}$ Gautier M, Valayer J, Odievre M, Alagille D. Histological liver cvaluation 5 years after surgery for extrahepatic biliary atresia: a study of 20 cases. J Pediatr Surg 1984:19:263-8.

5 Watanabe I, Ohi R, Okamoto A, Kasai M. Postoperative changes in the histologic picture of the liver in biliary atresia. In: Kasai M, Shiraki K, eds. Cholestasis in infancy. Tokyo: University of Tokyo Press, 1980:381-95.

6 Caccia G, Dessanti A, Alberti D. 8 years experience on the treatment of extrahepatic biliary atresia: results in 72 cases. In: Kasai M, ed. Biliary atresia and its related disorders. Amsterdam: Excerpta Medica, 1983:181-4.

${ }^{7}$ Kasai M, Sawaguchi S, Akiyama $\mathrm{H}$, et ul. A proposal of new classification of biliary atresia. Journal of the Japanese Society of Pediatric Surgery 1976;12:327-31. (in Japanese).

${ }^{8}$ Landing BH. Consideration of the pathogenesis of neonatal hepatisis, biliary atresia, and choledochal cyst: the concept of infantile obstructive cholangiopathy. Prog Pediatr Surg 1974;6: 113-39.

Correspondence to $\operatorname{Dr}$ A Dessanti, Department of Paediatric Surgery, Ospedale dei Bambini 'Umberto I', Via V Emanuele II 50,25100 Brescia, Italy.

Reprints from Professor R Ohi, Division of Paediatric Surgery, Tohoku University School of Medicine, 1-1 Seiryo-cho, Sendai 980, Japan.

Received 22 February 1985 